\title{
Evolution of Concrete/Formwork Interface in Slipforming process
}

\author{
T. Craipeau ${ }^{12}$, T. Lecompte ${ }^{1}$, F. Toussaint ${ }^{2}$, A. $_{\text {Perrot }}{ }^{1}$ \\ ${ }^{1}$ Institut de Recherche Dupuy De Lôme, Centre de recherche Christian Huygens, Lorient, \\ France \\ ${ }^{2}$ LafargeHolcim R\&D Center, Lyon, France \\ typhanie.craipeaullafargeholcim.com
}

\begin{abstract}
.
In a slipforming process, concrete is continuously poured and the formwork simultaneously raised so that the older concrete at the bottom supports the fresher at the top after a few hours of hydration. Such a complex process has to be industrially optimized to ensure the quality surface of concrete. The objective of the present work is to study the evolution of the concrete/formwork interface at very early age.

An experimental device has been designed in order to measure the evolution of the friction at this interface during the first hydration period. With cement hydration and thus water consumption, pore water pressure decreases and creates suction which could increase granular stress on the formwork. The role of pore water pressure on formwork friction is investigated. The first hydrates may also bond to the surface and create a strong adhesion at the same time.
\end{abstract}

Keywords: Interface, Friction, slipforming.

\section{Introduction}

Concrete can be formed using very different processes. Their common denominator is that the fresh and early age concrete properties have to be optimized regarding the way of forming. For instance, in order to be pumped and then cast inside a formwork, the concrete must be fluid enough to flow in the pipe but firm enough to resist bleeding or segregation.

An interesting process is the slipforming, where concrete is poured and the formwork raised continuously during hardening. "Smart Dynamic Casting" [1] is a 3D digital evolution of the slipforming process. The problem of optimizing concrete properties is very similar in both processes. Many questions, concerning fresh concrete, are linked with the interface conditions between the concrete and the moving formwork.

In a slipforming process, the formwork is in contact with concrete at different states of hydration. Concrete behavior changes drastically at the beginning of cement hydration. This technique, see Fig. 1, is a widely used construction methodology for high rise structures such as skyscrapers, pylons, silos or marine foundations that bene- 
fit from its high construction speed and the absence of cold joint that may affect the durability of the structure.

The concrete is directly in contact with the formwork from its fresh state to a set state without any demolding oil. During sliding, possible micro-cracking/lump formation can happen on the wall surface. These defects are most probably related to the concrete adhesion on the formwork [2]. These issues should be reduced and prevented to avoid a reduction of the durability of the structures that could turn into strong damages if not properly treated.
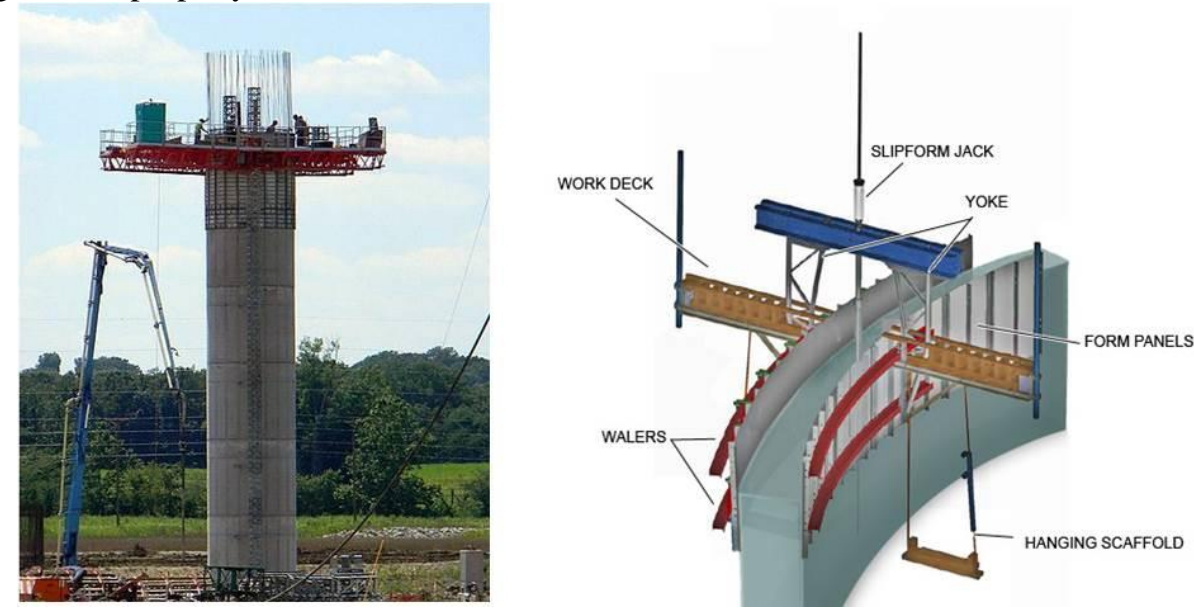

Fig. 1. Slipforming illustration

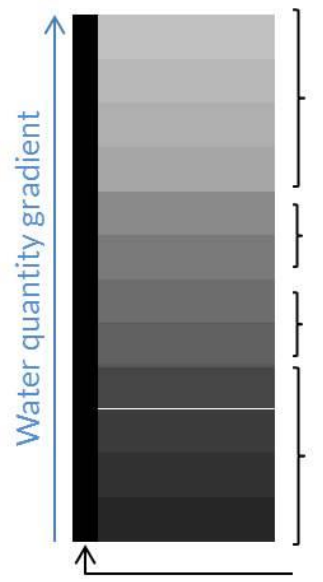

\section{Fresh Concrete}

Quasi-fresh concrete

Quasi hard concrete

$$
\begin{aligned}
& \text { Friction } \\
& \text { maximal with } \\
& \text { the formwork }
\end{aligned}
$$

\section{Hard concrete}

\section{Formwork}

Fig. 2. Concrete evolution inside a slipform formwork

The aim of this study is to improve our knowledge of the physical phenomena which govern friction and adhesion between concrete and various supports. The particularity of slipforming technique is that the walls are composed of a material exhib- 
iting a gradient of hydration state with concrete shifting from fresh state to early age (Fig. 2). Usually, the formwork is about 1.2 meters length, the concrete has to be set at the bottom of the formwork. The average speed is around 15 - 25 centimeters per hour. It has been shown that water consumption caused by cement hydration induces capillary suction which is assumed to play a major role on the interface [3]. It first induces pore water depression that increases granular stresses as the material behavior may become frictional with hydration [4]. Moreover, hydrates formation is expected to create a physical bond with the surface (Fig. 3). In order to appreciate the overall behavior, we attempt to evaluate the contribution of each phenomenon separately. An experimental device was built in order to measure the evolution of the friction behaviour of the concrete during the first hydration period. It is described later in this paper. Thereby, a multi-scale approach linking interfacial phenomena and cement hydration is proposed.

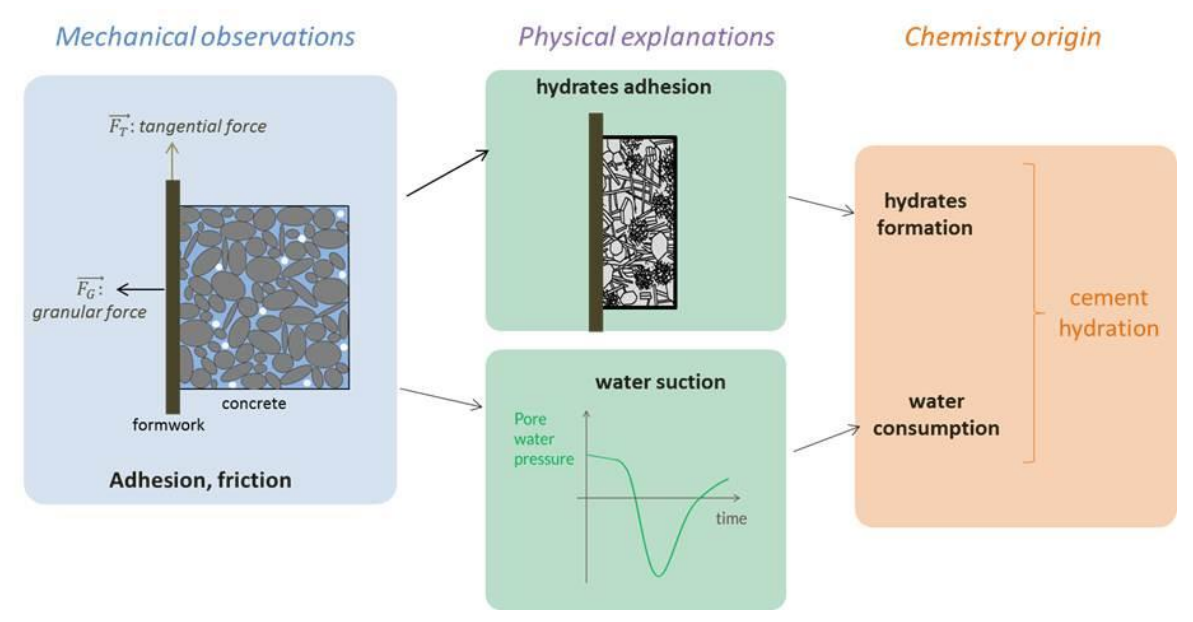

Fig. 3. Summary of granular forces origin

\section{Interfacial behavior of fresh concrete: physical phenomena}

\subsection{Chemistry origin and hydration consequences}

The origin of adhesion is the cement hydration. It firstly induces water consumption thus suction, (because of Le Chatelier contraction, see below) and hydrates formation which may bond to the surface as well.

The main hydration reactions of the Portland cement from the most reactive hydrate to the less one are presented below:

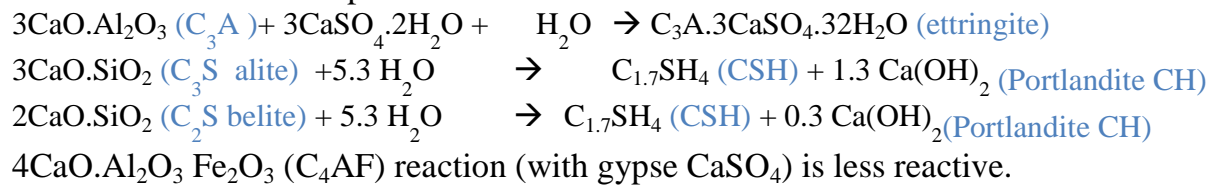


Those equations are important to keep in mind for the following results.

The sum of the initial volumes of water and cement is larger than the volume of the formed hydrates; this is called Le Chatelier contraction or selfdessication. Before Vicat setting time, the material can be considered as plastic matter: with contraction and hydrates formation, the grains will come closer together.

When the sample becomes harder, there is a percolation of the grains and the air will occupy the difference of water volume. Thus, the pressure of water will be in depressure compared to the atmospheric pressure. The capillary desiccation induces material shrinkage called as well endogenous shrinkage [5].

\subsection{Pore water pressure and granular stress (Terzaghi equation)}

Thanks to Terzaghi equation, suction can be related to the normal force. Terzaghi [8] describes that the total stress, $\sigma(\mathrm{kPa})$ is equal to the sum of the effective stress $\sigma$ ' (granular stress, $\mathrm{kPa}$ ) and the pore water pressure, uw $(\mathrm{kPa})$ :

$$
\sigma=\sigma^{\prime}+u_{w}
$$

The total stress of the concrete is considered in this study almost constant. Therefore, the effective pressure of the concrete only varies with concrete pore pressure. Terzaghi equation is illustrated in Fig. 4. At constant total constant, negative pore water pressure increases the stress $\sigma^{\prime}$ acting on the granular skeleton (which is the case in the early stage of hydration).

a)

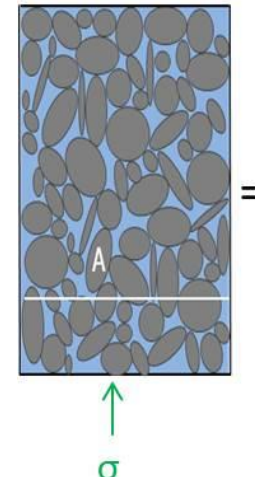

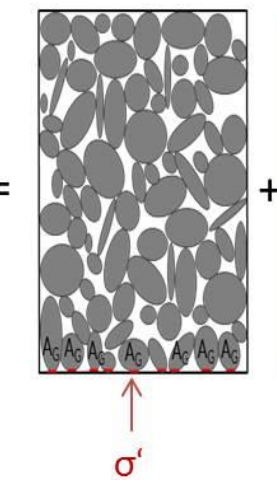

$\sigma^{\prime}$ b)
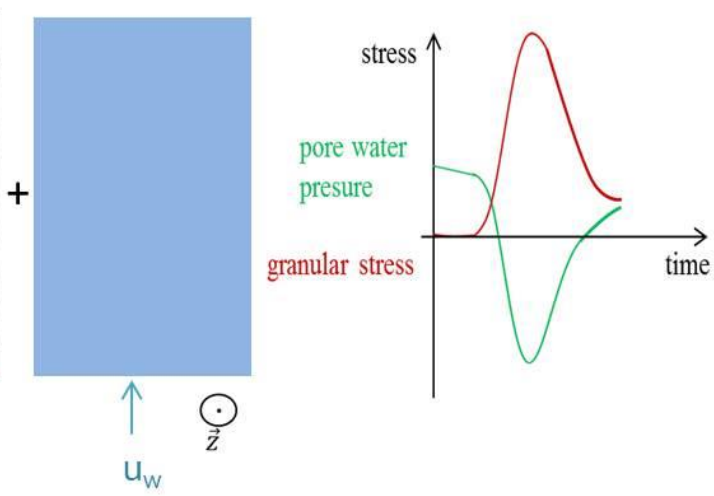

Fig. 4. Terzaghi equation illustration 


\section{Experimental procedures}

\subsection{Materials and mixing procedure}

The aim of the study is to understand the physical phenomena involved in the lifting resistance exerted by the concrete during the slipforming; therefore we chose usual materials: a Portland cement (CEM I 52.5N PM-ES CP2 NF), with $37 \mathrm{v} \%$ of a

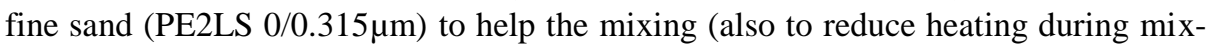
ing). A low Water/Cement ratio (here 0.3 ) is used to reduce strongly the pore water pressure. In order to obtain a low W/C ratio and a good rheology, a common polycarboxylate plasticiser admixture was used: Glenium 27 from BASF ( $0.063 \mathrm{wt} \% / \mathrm{cement})$.

In the fresh state, the mortar is fluid (slump ASTM is $260 \mathrm{~mm}$ ), and its air volume fraction is $2.7 \%$.

The designed mortar was prepared with a Perrier mixer with the same mixing protocol in order to ensure tests reproducibility. The sand was first mixed with part of the water at low speed $(140 \mathrm{rpm})$ during 1 minute. Then, after a waiting period of 4 minutes, cement is introduced and mixed at low speed during 1 minute. The rest of water is introduced during 30 seconds at low speed. Finally, the material is mixed at high speed (180 rpm) during 2 minutes.

\subsection{Device and procedure}

A specific device was developed. It consists of a parallelepiped box, filled with mortar. One face of the box, attached on a traction machine, can be moved and is made of the material that represents the formwork interface. A load cell permits to measure the global interfacial shear load (Fig. 5). It is also fitted with pore pressure sensors and force transducers to estimate those critical physical parameters. It allows to improve the understanding of the impact of suction on granular/interfacial friction and to assess its relative influence on the total stress. The advantage of this apparatus is to benefit from a "long run" of $400 \mathrm{~mm}$ enabling to approach slipforming kinematics (frequency and amplitude of lifts). For each lifting step, the lifting speed is 1 $\mathrm{mm} . \mathrm{s}^{-1}$ for a move of $5 \mathrm{~mm}$. The time at rest is 565 seconds between each step. The average lifting speed is then $0.5 \mathrm{~mm} \cdot \mathrm{min}^{-1}$. There are 67 lifting: the total test lasts around 11 hours. 


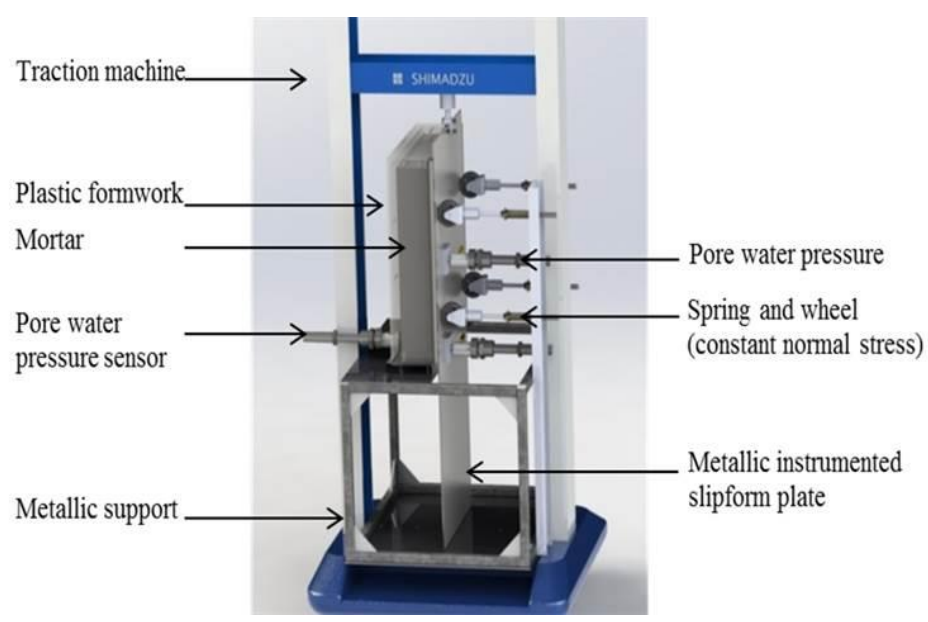

Fig. 5. Vertical shear stress device developed to study slipforming operations.

Pore water pressure is measured along the formwork using a pressure transducer device: a porous membrane is directly in contact with the concrete and is connected to a saturated chamber which allows obtaining a continuous water network to a pressure transducer [6] (Fig. 6). A relative pressure transmitter (Keller ${ }^{\circledR}$ PR33X) allows measuring and recording positive and negative pressure up to 1 bar.

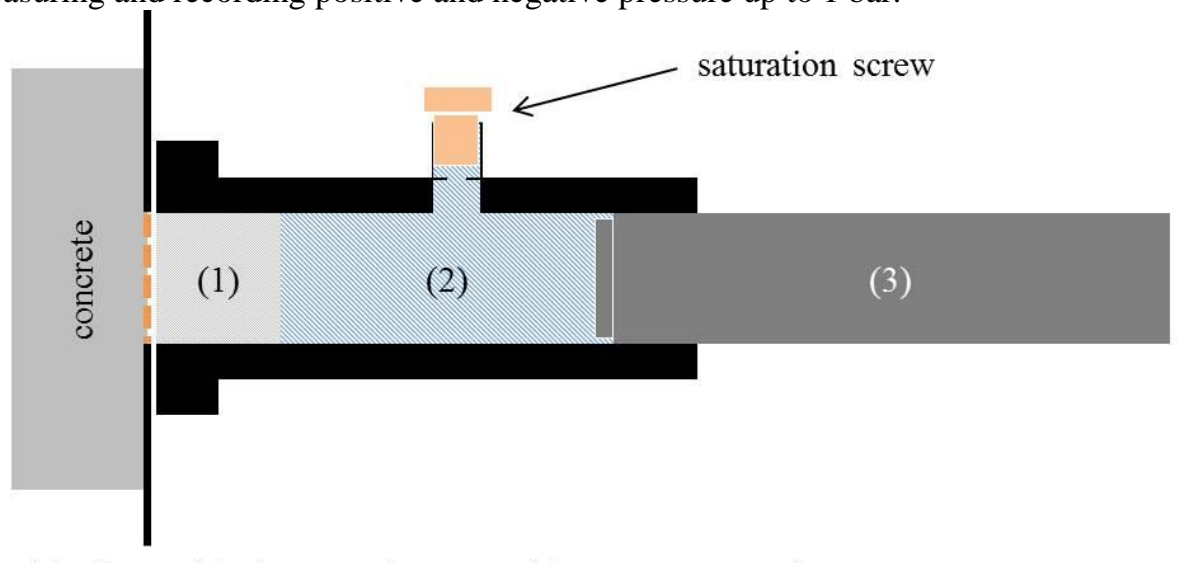

(1) Filter (2) de-aerated water (3) pressure transducer

Fig. 6. Pore water pressure measurement system 


\section{$4 \quad$ Experimental results and discussions}

\subsection{Cement hydration characterization}

Pore water pressure $\left(\mathrm{u}_{\mathrm{w}}\right)$, free water quantity evolution (determined with NMR relaxometry) and the volume variations (measured by hydrostatic weighting) are plotted versus the degree of hydration on Fig. 7. The degree of hydration is calculated from calorimetry measurements: it is defined as the ratio between the cumulated heat flow (which is the surfaces under the curve of the heat flow evolution over time) and the total theoretical enthalpy of the hydrates.

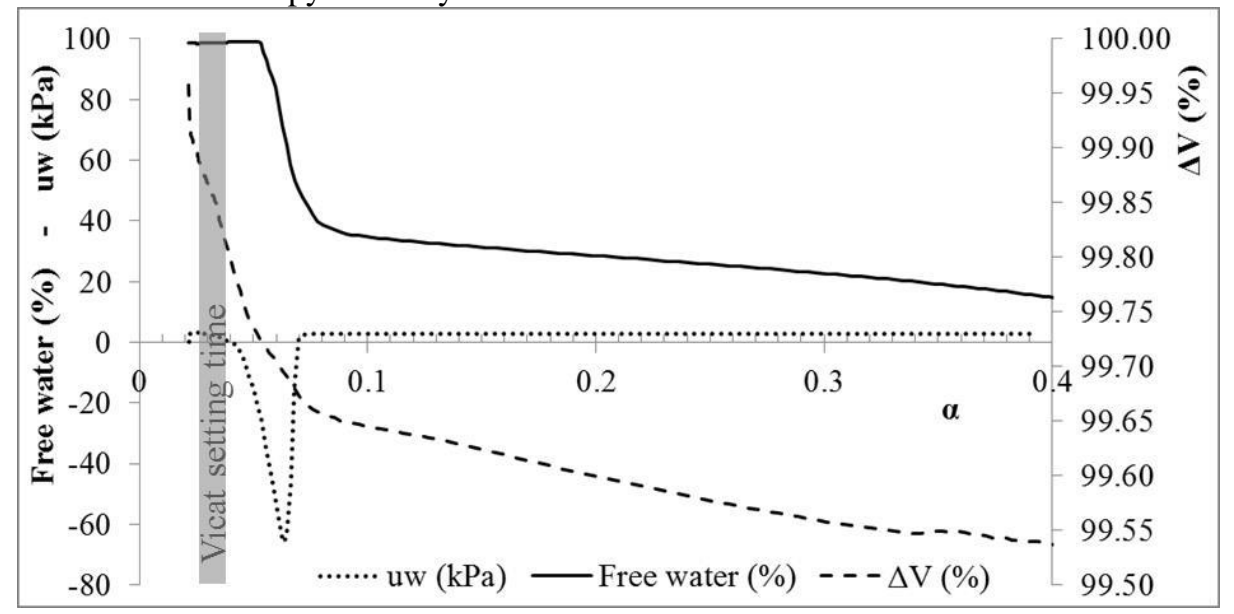

Fig. 7. Evolution of free water content, pore water pressure and volume variation during early hydration of the studied mortar.

Pore water pressure (dotted curve) is decreasing until the air network becomes continuous and connected with ambient atmospheric pressure, if an air drop comes in contact with the sensor the pressure comes back to positive values.

The volume (dashed curve) decreases faster when pore water pressure is decreasing. After that, it continues to decrease but the slope is lower. Free water quantity (continuous line)-obtained thanks to RMN relaxometry- is constant at the beginning and then water is consumed faster [7]. This means that a small amount of consumed water will induce a strong structuration of the material [4]. Thus, we see that the evolution of the three parameters is correlated and can be separated in two periods. Below $\alpha=0.07$ the hydration and water consumption is low. Above $\alpha=0.07, \mathrm{CSH}$ precipitation begins significantly. The system becomes rigid, pore water pressure and the quantity of water drop suddenly. We can see that pore water pressure, free water quantity, volume variations are strongly linked to hydration degree of cement. 


\subsection{Tangential stress}

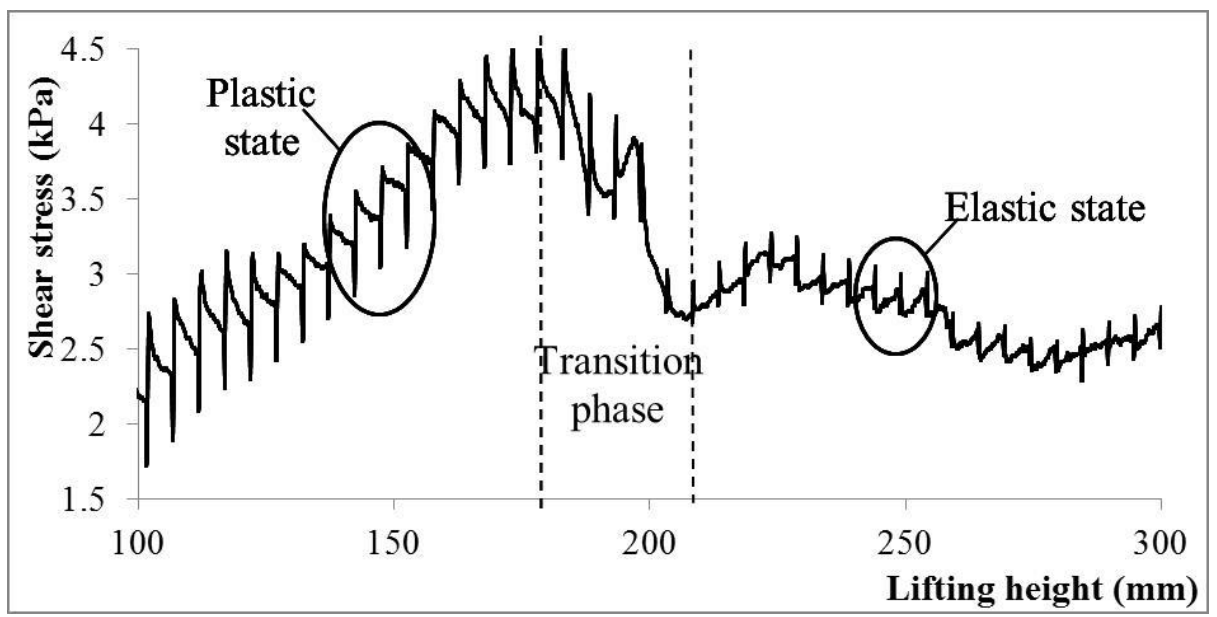

Fig. 8. Mortar behavior evolution illustration: change in behavior type

The measured shear stress as a function of the lifting height is plotted (Fig. 8) between 100 and $300 \mathrm{~mm}$ of lifting.

The behaviour of the mortar is changing over hydration time. In the first period, it has a viscoplastic behaviour: the shear stress decreases during the rest period indicating material relaxation. Then after a transition phase, its behaviour changes to an elastic solid state: between two liftings the shear stress increases.

Mortar yield stress and the interface tangential stress are plotted on the same graph to evaluate the influence of the structural build-up of the mortar (i.e. evolution of the yield stress before setting time in dotted line) on the tangential stress (continuous line) (Fig. 9). The tangential stress evolution is obtained with our experimental device (paragraph 3.2). The yield stress is measured thanks to a Vane test.

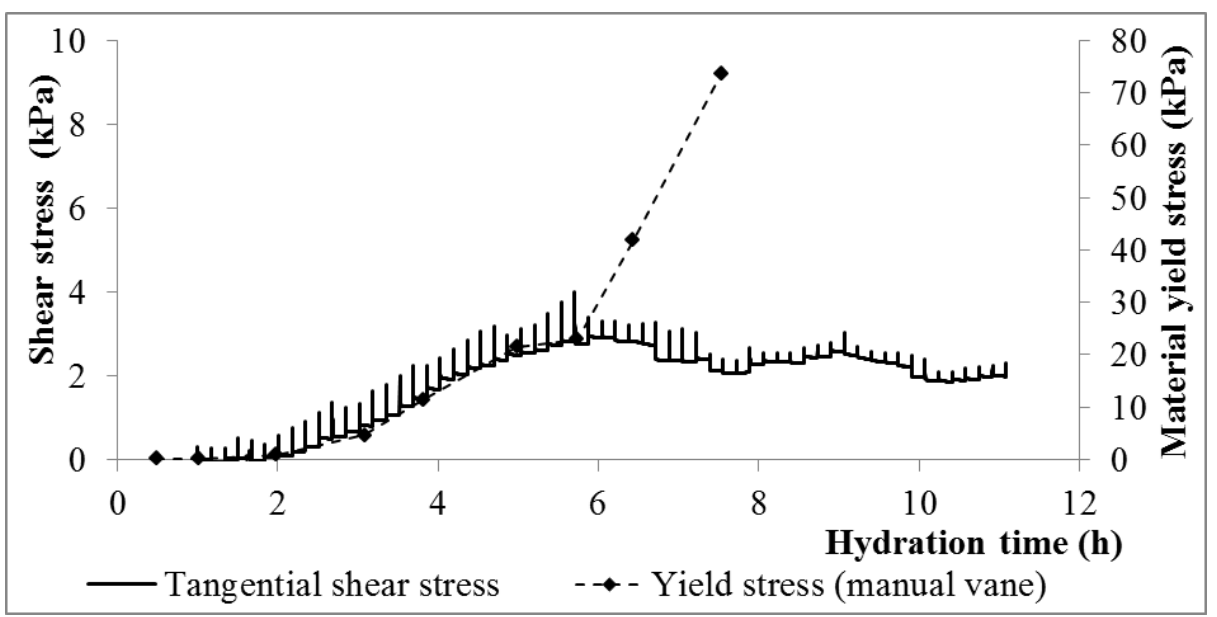


Fig. 9. Evolution of mortar yield stress evolution and tangential stress evolution measured during lifting operation using the developed device

Fig. 9 shows that there is a scaling between mortar yield stress and the average interfacial tangential stress with a factor 8 (comparing the y axis scales) until 6 hours of hydration time which is one hour after the end of Vicat setting time. We can observe that after 6 hours the yied stress increases drastically whereas tangential decreases a little. This indicates that after 6 hours solid-solid friction is measured.

\subsection{Friction law}

The lifting operation of slipforming is carried out with mortar running from fresh state where it presents a viscoplastic fluid-like behavior to a set state where it has reached an almost elastic solid-type behavior. It can be noted that between those two extreme states, the mortar exhibits frictional behavior. The lifting force must overcome the adhesion and the friction on the metallic panel before the sliding starts. This force peak is called static lifting stress. After the first movement, the force required to lift the plate is decreasing as adhesion is cut off and only friction should be overcome (Fig. 10). The minimum friction that occurs during sliding is called sliding lifting stress. The difference between the static lifting force and the sliding lifting force will be called adhesion and the sliding lifting force resulting is only friction [8].

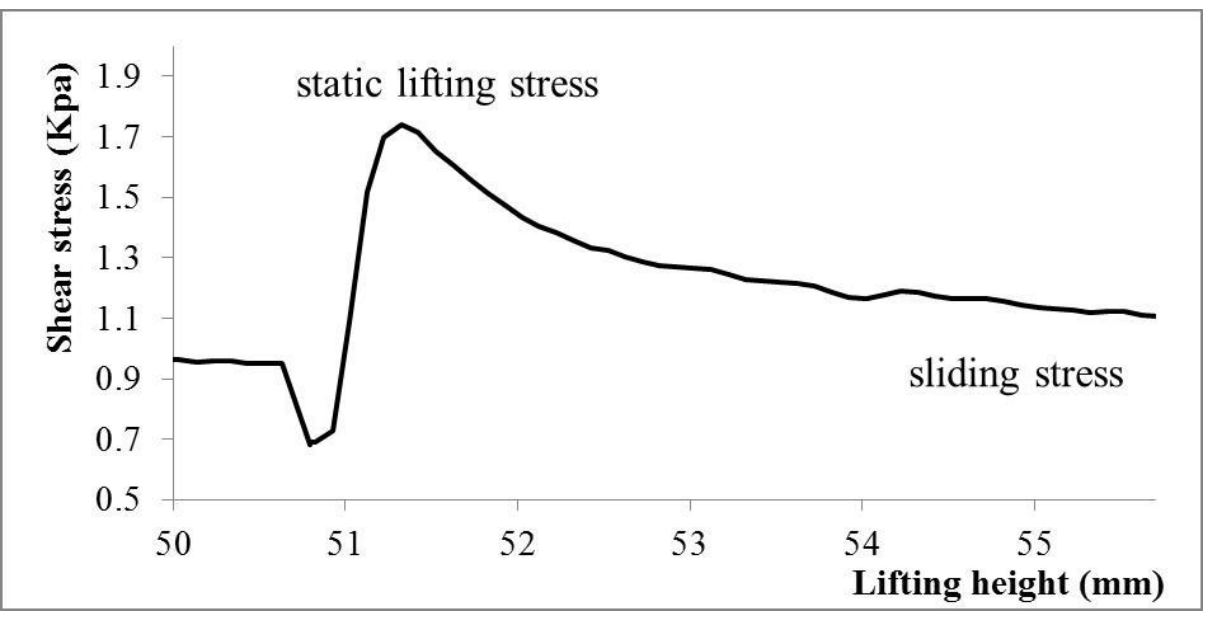

Fig. 10. Illustration of static lifting stress and sliding stress

During one cycle (Fig. 10), it seems that the formwork movement induces a shear stress reduction.

It has been shown in [8] that the lifting force is proportional to the effective stress of the concrete on the panels. The relation is described by the adhesion and friction laws: 


$$
\begin{aligned}
& \mu_{\text {static }}=\frac{F_{\text {Static }}}{\sigma^{\prime}} \\
& \mu_{\text {sliding }}=\frac{F_{\text {sliding }}}{\sigma^{\prime}}
\end{aligned}
$$

With: $\mathrm{F}_{\text {static }}=$ static friction stress $[\mathrm{kPa}] ; \mathrm{F}_{\text {sliding }}=$ sliding friction stress $[\mathrm{kPa}] ; \mu_{\text {static }}=$ static friction coefficient $[-] ; \mu_{\text {sliding }}=$ sliding friction coefficient $[-] ; \sigma^{\prime}=$ effective stress $[\mathrm{kPa}]$.

The effective stress represents the stress between the solid particles and the slipform panels.

\subsection{Hypothesis of mechanisms}

The evolution of pore water pressure and tangential shear stress obtained with the design device are plotted in Fig. 10. We observe that the order of magnitude of the pore water pressure (dotted line) is really higher than the tangential shear stress (continuous line). For a first interpretation of the results, to see if there is a correlation between those two distinct measurements, we zoomed between 0 and 8 hours of hydration and we plotted the opposite of the addition of pore water pressure and hydrostatic pressure of the mortar (Fig. 12).

It seems that those two measures are related: the calibrated pore water pressure seems to increase with the maximum of the peaks of the tangential shear stress. Comparing the two different y-scales of Fig. 12, a friction coefficient of about 0.4 can be computed. Considering a constant total shear stress, as proposed by Terzaghi theory, the granular stress should fluctuate with the opposite of the pore water pressure. This is in agreement with our measurements until 7 hours when the water network becomes discontinuous (thus Terzaghi equation cannot be apply because we are not in saturated condition). Those first results have to be confirmed.

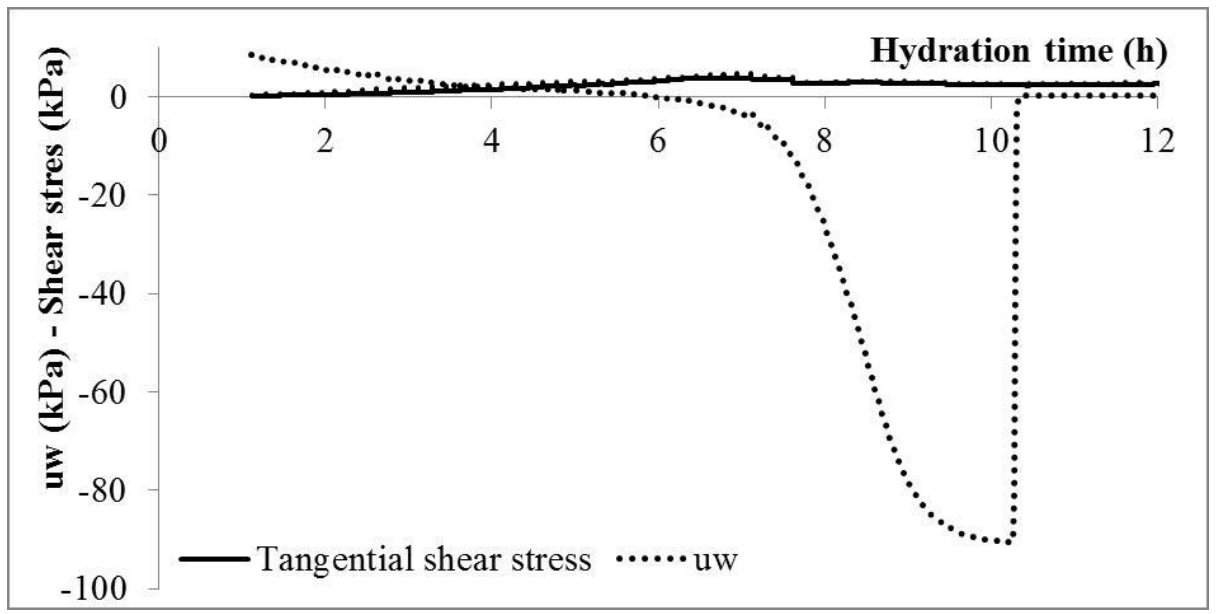

Fig. 11. Pore water pressure and shear stress evolution measured with the experimental device. 


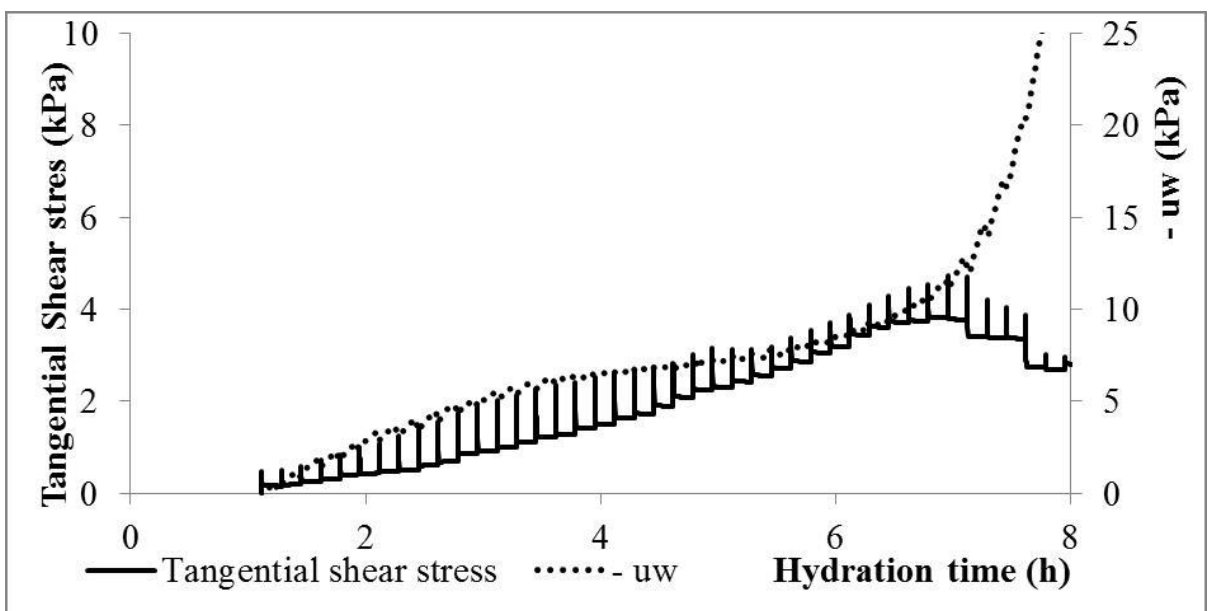

Fig. 12. Zoom of calibrated pore water pressure and shear stress evolution measured with the experimental device.

\section{$5 \quad$ Conclusion and perspectives}

We characterized water consumption, caused by cement hydration which induces hydrate bonding to the surface on one hand and material shrinkage which drives the pore water depressure on the other hand. As a result, there is an increase of the granular strength on the formwork. Thus, we estimated a friction coefficient by the tangential shear stress.

Our first results show an interesting correlation between structuration of the material and the transition state between liquid to solid-type behaviour.

Terzaghi equation seems to be valuable during the first state when water network is continuous. After that, the air void quantity is increasing, water network is not continuous anymore, pore water pressure and friction increase, and the granular shear stress decreases as we have solid-solid friction with the evolution of the structuration of the material.

\section{Acknowledgements}

The authors are thankful to Agata M. Gajewicz and Prof. Peter McDonald (University of Surrey) for allowing us measuring the water consumption with relaxometry NMR and there useful feedbacks.

The authors also wish to thank Alexandre Menguy which made the drawings of the experimental device.

\section{REFERENCES}


[1] Lloret, Ena et al. « Complex Concrete Structures ». Computer-Aided Des. 60 (2015):40-49

[2] Internal document J. N. Rivoal Low adhesion caisson concrete

[3] Hammer, T. A., «The use of pore water presure to follow the evolution from fresh to hardened concrete », 2006 (e-ISBN: 2351580028) RILEM Publications SARL.

[4] L. K. Mettler, F. K. Wittel, R. J. Flatt, et H. J. Herrmann, « Evolution of strength and failure of SCC during early hydration », Cem. Concr. Res., vol. 89, p. 288- 296, nov. 2016.

[5] Barcelo, L, «Influence des caractéristiques des ciments sur la stucturation et le comportement dimensionnel des matériaux cimentaires au jeune âge », Ecole normale supérieure de Cachan, 2001

[6] T. Lecompte, A. Perrot, V. Picandet, H. Bellegou, et S. Amziane, « Cement-based mixes: Shearing properties and pore pressure », Cem. Concr. Res., vol. 42, no 1, p. 139-147, janv. 2012

[7] A.M. Gajewicz, E. Gartner, K. Kang, P. J. McDonald, et V. Yermakou, «A 1H NMR relaxometry investigation of gel-pore drying shrinkage in cement pastes », Cem. Concr. Res., vol. 86, p. 12-19, août 2016

[8] Fossaa, K. T. Slipforming of Vertical Concrete Structures. Friction between Concrete and Slipform Panel. (Fakultet for ingeniørvitenskap og teknologi, 2001). 